\title{
A PRIMEIRA ANÁLISE DA CONSTITUIÇÃO DE $1824(*)$.
}

\author{
BRASIL BANDECCHI \\ do Departamento de História da Faculdade de Filo- \\ sofia, Letras e Ciências Humanas da Universidade de \\ São Paulo e da Faculdade de Filosofia, Ciê.zcias e I.e- \\ tras de Franca.
}

Impresso o Projeto de Constituição do Império, redigido pelo Conselho de Estado, organizado no dia 13 de novembro de 1823, ou seja no dia seguinte à dissolução da Constituinte ,D. Pedro I ordenou que se enviasse exemplares às Câmaras Municipais, a fim de que se manifestassem sobre o mesmo (1).

Podiam, assim, as Câmaras apresentar sugestões e emendas, recomendando-se, posteriormente, que fosse ouvido o povo, a exemplo do que acontecera no Rio de Janeiro, onde o Senado da Câmara afixou edital em que convocava quantos quisessem se manifestar sobre a Projeto, sendo que os que fossem favoráveis deviam assinar em um livro e os contrários, noutro. No edital de convocação, entretanto, o Senado fazia a defesa do Projeto, no qual encontrou

"prova não equivoca do liberalismo de S. M. Imperial, do seu Ministério e do seu Conselho" (2).

(*). - Comunicação apresentada na 1.a Sessão de Estudos, no dia 5 de julho de 1972 (Nota da Redação).

(1). - Decisão "No 179 - Império - em 17 de dezembro de 1823. Remete às Camaras o Projeto de Constituição. - S. M. o Imperador, fiel à promessa, que fez, de oferecer às Camaras deste Império um Projeto de Constituição: Manda, pela Secretaria de Estado dos Negócios do Império, remeter ao Ilmo. Senado da Camara desta Cidade os inclusos exemplares. - Palácio do Rio de Janeiro em 17 de dezembro de 1823. - João Severiano Macicl da Costa. - Na mesma conformidade e data se expediram portarias a todas as Camaras das Províncias deste Império". Coleçãa das Decisões do Governo do Império do Brasil de 1823, Rio de Janeiro, Imprensa Nacional, 1887.

(2). - O edital vem reproduzido na Coleção de Decisóes citada. 
Das Câmaras que enviaraın emendas, a de Itu tem, com Justiça, sido das mais citadas e muitas vezes a única. Entre os cidadãos probos escolhidos para apresentarem observações ao Projeto encontravam-se homens da envergadura de um Feijó, de um Paula Sousa, o que, por si só, indica a importância dessa mạnifestação.

No rol das Câmaras que enviaram sugestóes ou deram parecer, jamais vimos a de Caeté, razão pela qual entendemos como sendo inédito, o documento que ora apresentamos a este ilustre e douto congre'so (3).

O documento em tela, motivo desta comunicação, pertence ao valioso Arquivo do Instituto Histórico e Geográfico de São Paulo e seu redator revela conhecimentos de Direito Constitucional que lhe dá autoridade no estudo que fez do Projeto, tendo mesmo, em alguns passos, levado suas observações para o campo de Direito Comparado.

Está datado da

\footnotetext{
"Vila do Caeté em Vereança Geral de 6 de fevereiro de 1824" e assinado: "pelo Juiz (...) (?), o Sargento-Mor Manuel José Pires da Silva Pontes".
}

Existindo na toponímia brasílica diversos Caetés, procuramos, inicialmente o Indice dos topônimos contidos na Carta do Brasil 1:1000.000 do IBGE, organizado por P. E. Vanzolini e N. Papavero e encontramos nada menos de 13 lugares com esse nome, sendo que só em Minas Gerais, para onde endereçamos nossa atenção inicial, havia 3 .

Desta forma, nos a primeira preocupação, foi saber em que Província se localizava a Vila de Caeté, em 1824, se era a única ou se existiam outras com o mesmo nome. Como sabemos as informações históricas dos nossos municípios não são das melhores e nem as mais seguras. Pareceu-nos que procurando fontes da época, pelo pequeno número de vilas criadas, em relação ao avultado que atualmente possuimos. A mais autorizada fonte que encontramos foi o Dicionáric Geográfico, Histórico e Descritivo do Império do Brasil, contendo a origem e história de cada Provincia, Cidade, Vila e Aldeia etc., por J. O. R. Milliet de Saint Adolphe e traduzido por Caetano Lopes de

(3). - Este documento é um daqueles que ilustrarão nosso estudo sobre - "Poder Moderador" o qual pretendemos terminar no correr do próximo aro. 
Moura, publicado em Paris, em 1845, em Casa de J. P. Ailland, Editor.

O tradutor, no Prólogo que escreveu para a obra, diz que

"M. Milliet de Saint Adolphe, no longo espaço de 26 aros que residiu no Brasil, depois de haver compulsado quantos livros pode encontrar na Biblioteca Imperial do Rio de Janeiro e consultado as obras dos escritores modernos, pôs um estudo particular em se informar miudamente de tudo quanto dizia respeito às diferentes cidades, vilas e provincias, peregrinou por muitas delas e com uma paciência digna dos maiores elogios foi fazendo assento dos decretos, leis e decisões do governo concernentes à criação de novas províncias, comarcas, vilas e freguesias, à fundação de hospitais, abrimento de estradas, construção e lançamerio de pontes e mais providências de reconhecida utilidade pública $e$ classificando cópia imensa de materiais que havia coligido por ordem alfabética e de tão longo e consciencioso trabalho resultou o presente Dicionário histórico, descritivo e geográfico, cuịa ntilidade é tão evidente que não seria necessário encarecê-la".

Analisando a autoridade do Dicionário e levando em consideração a época em que foi elaborado, sentimo-nos seguros em aceitar que em 1824 só havia um único município com o nome de Caeté, também chamado Vila Nova da Rainha.

Do verbete, destacamos:

"Caeté, ou Vilanova-da-Rainha. Antiga vila da província de Minas Gerais, 3 léguas ao sueste de Sabará, e 18 ao nordesce da cidade de Mariana, em 19 graus e 54 minutos de latitude. Seu nome primitivo é derivado das palavras indianas caá, que significa montanha, e etê, mata espessa. Diversos aventureiros se estabeleceram numa planície onde o ouro se achava à flor da terra, e ali formaram uma povoação que se aumentou rapidamente. Quando o governador de São. Paulo e de Minas, Antônio de Albuquerque Coelho, quis estabelecer neste país um posto militar, e assentar as bases da arrecadação dos direitos sobre o ouro, revultaram-se seus habitantes tendo por cabeças os dois irmãos paulistas Jerônimo e Velentino Pedroșo. Nesta circunstância, o governo português se houve com bravura, e D. Brás Baltazar da Silveira, que sucedeu a Antônio d'Albuquerque, conferiu em 1714 à povoação de que tratamos o título de vila, com o nome de Vilannvada-Rainha, prevalecendo o de Caeté com o qual é. vulgarmente conhecida". 
Desta forma, confirmava-se nossa primeira suspeita de que o documento que examinávamos era de procedência mineira .

O título desta comunicação pode causar estranheza, dando à Câmara de Caeté a primazia na análise do Projeto, quando a de Itu apresentou emendas importantes (que não foram atendidas) e teve atitude altiva e corajosa ao não aceitar a sugestão da Câmara do Rion de Janeiro, que era de aprovar o Projeto sem apresentar emendas.

"Muito sentimos (...) não poder concordar com Vossas Se nhorias - diz a resposta ituana - pela diferente circunstinncia em que nos achamos. O povo desta Capital (como Vossas Senhorias afirmam) manifestamente tem declarado o seu kesejo nelo juramento do Projeto, como Constituição do Império que deve durar para sempre; o povo desta Vila pelo contrário parece conforme em julgar impraticáveis alguns artigos, e outros poucos vantajosos ao Brasil, e persuade-se ser do maior interesse o juramento do mencionado Projeto, mas com algumas alterações" etc.

E envia suas Refleões sobre o projeto de Constituição, que receberam as assinaturas do Padre João Paulo Xavier, José Galvão de Barros França, Diogo Antônio Feijó, José Rodrigues do Amaral e Melo, Cândido José da Mota, Fernando Dias Pes Leme, Padre Manuel Ferraz de Camargo, Francisco Leite Ribeiro, Antônio Pacheco da Fonseca e João de Almeida Prado (4) .

Na verdade, as Reflexões constituem Emendas, analisam os artigos emendados, mas não são uma Análise do Projeto. Podem, inclusive, serem muito mais importantes do que o contido no documento que apresentamos. Mas este não é o caso. O documento analisa o Projeto. E esta é nossa afirmação.

O documento em foco, aprovado na Vila de Caeté em vereança geral, atende à orientação do Senado da Câmara do Rio, pois que termina por rogar a $D$. Pedro que

"haja por bem jurar e mandar jurar e observar" 1930.

(*). - Francisco Nardy Filho, A Cidade de Itu, II, pp. 150-156. São Faulo, 
c Projeto como Constituição Política do Império.

Mesmo assim e sem apresentar emendas, a análise que faz do Projeto é interessante e erudita. Seu relator não só leu atentamente o Projeto, mas também o comparou com as constituições de outros países, o que o levou a proclamar o

"civismo de Sua Majestade Imperial e a sabedoria do seu Conselho de Estado".

Destaca que

"A soberania, a Indeperdência e a Liberdade da Nação Prasileira tão solenemente proclamadas, que não admitem laço ou Confederação alguns com qualquer outra Nação, que as inva!ide; o Senhor D. Pedro I, nosso Imperador e Defensor Perpétuo do Brasil; a Dignidade Imperial Hereditária na sua Família; os elementos da Monarquia docemente combinados com os do Governo Popular; a Santa Religião dos nossos Pais mantida triunfante; o Fanatismo desterrado; e a Tolerância, sempre bem vinưa filha do Céu convidando das nossos praias os Povos opressores da Europa, tais são $(\ldots)$ as primeiras pedras, que se lançaram ao majestoso Edifício Político do Império".

Pelo citado, vê-se que estamos frente a adepto fervoroso do Imperador a dos princípios consagrados no Projeto. Ficasse apenas nisto e pouco valor teria o documento. Mas não, como já dissemos, a ahálise é erudita.

Conhece bem o funcionamento do Poder Moderador, que diz ser um venturoso invento e que os ingleses já o haviam introduzido na sua Monarquia Constitucional e que se tratava do

"gênio da harmonia descido dos Céus para auxiliar os três poderes, manutenir os nossos Direitos e verificar as garantias "particulares".

Todo o documento é uma análise do Projeto de Consttiuição que veria a se transformar na Lei Magna do Império, sancionada em 25 de março de 1824 .

A obra de Benjamin Constant lhe é familiar e com ela sustenta a legitimidade do Quarto Poder. 
"O Monarca Hereditário (acentua Benjamim Constant) deve ser irresponsável, e inviolável; êle é a pedra angular, que fixa o remate do Edifício Político".

O artigo 98 da Constituição de 1824 consagraria que

"o Poder Moderador é a chave de toda a organização nolítica, é delegado privativamente ao Imperador, como Chefe Supremo da Nação, e seu primeiro representante, para que incessantemente vele sobre a manutenção da Independência, equilíbrio e harmonia dos mais poderes políticos".

E o artigo 99 diz que

"a pessoa do Imperador é inviolável e sagrada: ele năo está sujeito a responsabilidade alguma".

O documento objeto desta comunicaçã̃o enfoca os pontos funda.mentais do diploma, como a religião católica declarada oficial, a representação da nação, a harmonia e independência dos poderes, o poder moderador e sua relação com os demais poderes políticos, a constituição das câmaras legislativas, a iniciativa das leis, os conselhos provinciais, a agricultura, comércio, artes etc., a responsabilidade dos ministros, as garantias individuais.

A análise é do Projeto, mas como o Projeto transformou-se em Constituição pura e simplesmente, há de se admitir que a análise ć da própria Constituição.

Pelo exposto, concluimos:

1). - Ao que sabemos, este documento nunca foi divulgado e nem referido, daí sua apresentação como inteiramente inédito.

2).. - A Câmara de Itu apresentou emendas, mas não uma análise de todo o Projeto.

3). - O parecer da Câmara de Caeté é o primeiro estudo completo feito do Projeto de Constituição a como este se transformou na Constituição tal como foi apresentado, é também o primeiro estudo da própria Lei Magna do Império. 